\title{
Empathic design: Research strategies
}

\section{Joyce Thomas and Deana McDonagh}

\section{School of Art and Design, Beckman Institute, University of Illinois at Urbana-Champaign}

\section{REVIEW}

Please cite this paper as: Thomas J, McDonagh D. Empathic Design: Research strategies. AMJ 2013, 6, 1, 1-6. http//dx.doi.org/10.4066/AMJ.2013.1575

Corresponding Author:

Professor Joyce Thomas

Visiting Scholar

Beckman Institute for Advanced Science and

Technology

University of Illinois (Urbana-Champaign)

405 North Mathews Avenue

Urbana, IL 61801 USA

\section{Abstract}

This paper explores the role of empathy within new product development from the perspective of human-centred design. The authors have developed a range of empathic design tools and strategies that help to identify authentic human needs.

For products and services to be effective, they need to satisfy both functional and emotional needs of individuals. In addition, the individual user needs to feel that the product and/or service has been designed 'just for them', otherwise they may misuse, underuse or abandon the product/service. This becomes critical with a product such as a Zimmer frame (walker), when it fails to resonate with the patient due to any stigma the patient may perceive, and thus remains unused.

When training young designers to consider the wider community (people unlike themselves) during the design process, it has proven extremely valuable to take them outside their comfort zones, by seeking to develop empathy with the end user for whom they are designing. Empathic modelling offers designers the opportunity to develop greater insight and understanding, in order to support more effective design outcomes. Sensitising designers to the different ways that individuals complete daily tasks has helped to diminish the gap between themselves and others (e.g. people with disabilities).
The authors intend for this paper to resonate with health care providers. Human-centred design can help to refocus the designer, by placing the individual end user's needs at the heart of their decision-making.

Key Words

Empathy, human-centred design, research strategies, shared language, authentic human behaviour

\section{Developing a human-centred approach}

All too frequently developers feel compelled to dive into the design solving process (the 'how') without fully exploring, considering or reflecting on the user and user context (the 'why'). As part of the designing process and creative problem-solving approach to new product innovation, it is important to clarify human needs and motivation, before focusing on the final design outcome (the 'what'). Sinek ${ }^{1}$ introduced the concept of 'the Golden Circle' that has three layers (Why, How, and What) (Figure $1)$. The inner circle relates to 'why' we are motivated to pursue our goals (e.g. ambitions, philosophy). The middle circle relates to 'how' we achieve our goals (e.g. particular actions), and the outer circle focuses on 'what' has been the outcome of the process (e.g. product, shift in practice). For example, Apple designs, develops and manufactures computers and related devices (the 'what'). It gives the consumer an intuitive means of communication and data storage (the 'how'). But what makes this company so successful in the market place is the 'why'. The why inspires people to buy-in to your product, belief or practice in the long term. If something resonates with you on a deeper level, it builds loyalty and generates a real shift in behaviour. This 'Golden Circle' model applies to the process of human-centered innovation.

Figure 1: The Golden Circle ${ }^{1}$

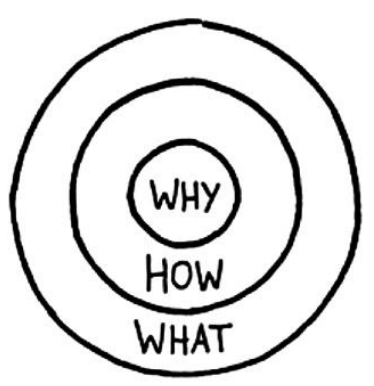

In the design solving process for services and products, it 
is critically important to observe and understand the 'why' from the point of view of individuals in the population under consideration. An effective human-centered design approach addresses not only the functional requirements, but also the emotional needs of the users.

You want to avoid developing products and services that are valueless to people because they do not respond to authentic human needs. If you develop products that appear to satisfy functional needs that could change the world, but they do not resonate with the people who will use them, the products (physical products, services, protocols, experiences) will be underused, misused, or abandoned. If you develop products that do not work, people will dispose of them or even worse, people may be injured.

\section{Function and emotion}

Figure 2 represents a series of products that could typically be found on a bathroom counter. While the product containers may function well for manufacturing, shipping and delivery to the end user, the product language (product semantics and/or graphics) does not distinctly identify whether the contents are for internal use, external use, or even for human use. In low light or impaired vision situations, even the product graphics may not be enough to prevent unintended misuse.

Figure 2: Which tube contains toothpaste and which is the haemorrhoid cream?

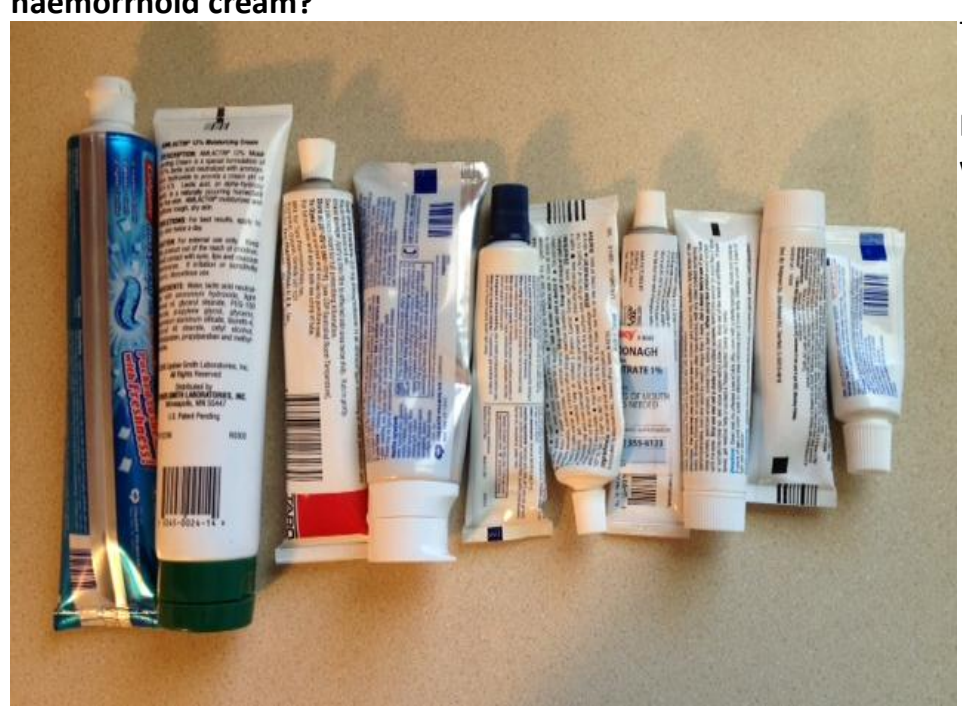

Following government requirements ${ }^{2}$ is not always the answer. While satisfying the legal requirements, you still may neglect the authentic human experience. In the example shown in Figure 3, a legally blind man reads a Braille sign that can only be accessed by climbing on a piece of furniture (only $10 \%$ of individuals who are blind in the USA read Braille).
Figure 3: Extreme functional failure: Braille signage meets regulatory requirements but not user needs
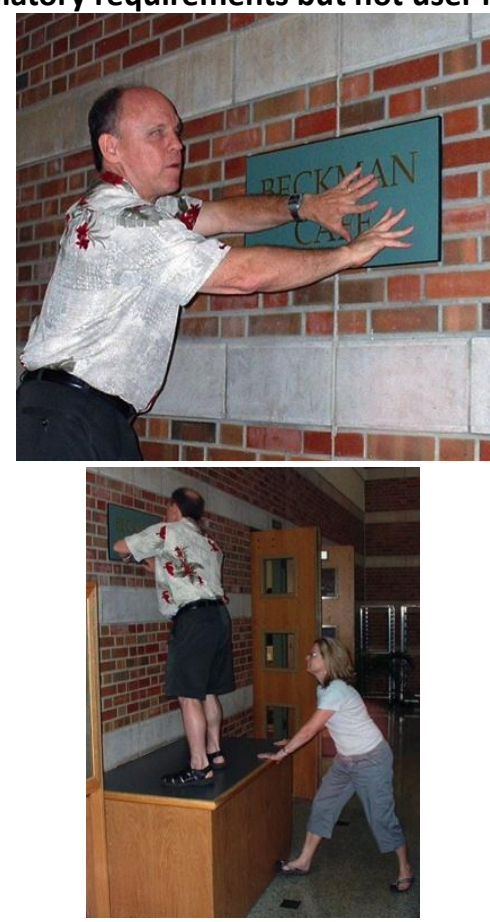

Products can also evoke strong emotional responses in humans that can lead to purchase desire, retention of old and or/unused products, or even product abandonment. In Figure 4, the shape and colour of the pepper grinder called to one of the designer/authors from across the shop first bringing the compelling reaction "I must have that", followed by the question "what is it?"

\section{Figure 4: Extreme emotional connection: Functionality} was not the main focus

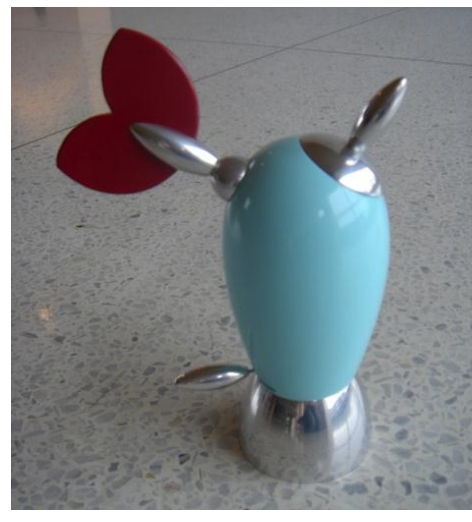

A conversation with users about products in their possession that they 'love' or 'hate' reveals that emotional connections to products can be related as much to the giver of the product as the product itself. In Figure 5, a group of young adults discuss their emotional connections to products they own. Exploring both the utilitarian and supra-functional/emotional (e.g. users' style, lifestyle, aspirations) ${ }^{3}$ provide cues to ensure better design outcomes. 
Figure 5: A student discussion of 'Love It or Hate It' products they have at their temporary college housing

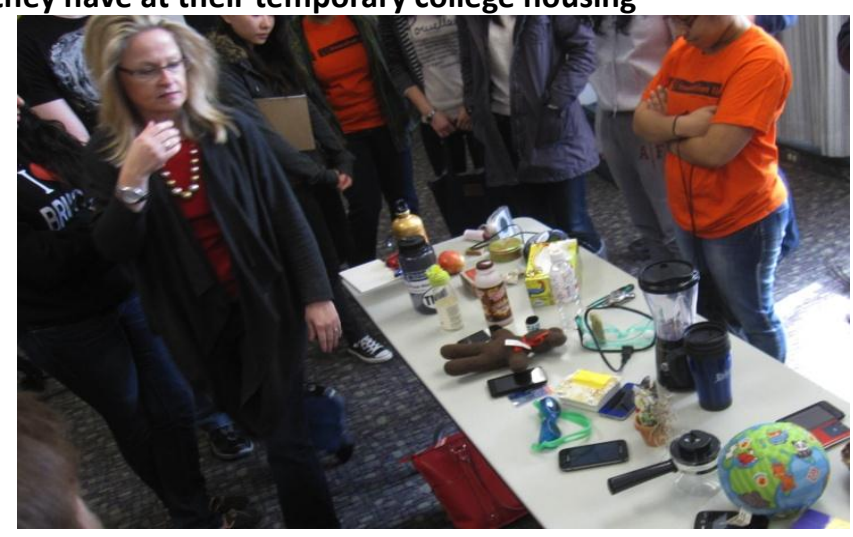

In Figure 6a, a young woman uses a Zimmer frame (walker) after surgery. If she feels stigmatised by her own internal image of a person using this product (6b) and she abandons its use, the results of her surgery and healing could be significantly reduced.

Figure 6 a \& b: Products that evoke a perception of stigma may be abandoned. (Kzenon / Shutterstock.com)
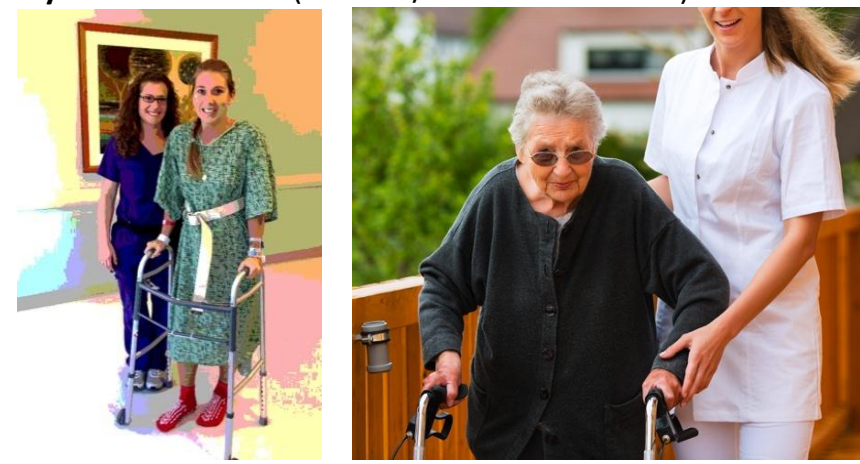

\section{Empathy}

Empathy is "our intuitive ability to identify with other people's thoughts and feelings - their motivations, emotional and mental models, values, priorities, preferences, and inner conflicts". 4

Even though products are mass-produced, in the $21^{\text {st }}$ Century users need to feel like the products were designed 'just for $m e^{\prime}$. Designers and developers of products and services need to rely on the importance of developing empathy with users to ensure that these products will resonate with individuals as opposed to the masses.

Empathy enables designers to gain intimate insights and understanding into human experiences. As individuals have grown more discerning regarding products and services, they use them to satisfy personal and functional as well as emotional needs. Designing in the scientific mode (research conducted at a distance from participant) fails to generate holistic outcomes. Empathy becomes a critical component in human-centred research.

\section{Empathic research strategies}

Product developers rarely operate in isolation. Their ability to work in teams, communicate to other professionals, elicit authentic human needs, understand emotional needs, and then translate them into tangible design outcomes is critical.

In utilising empathic research strategies, both the designer and user are dynamic elements in the process. This approach emphasises an internal shift within the designer in order for empathy and deep understanding to develop. It requires the designer to acknowledge and expand their "empathic horizon"5,6,7 - boundaries of understanding and knowledge - which can take the designer outside of his or her own comfort zone.

Empathic research strategies incorporate shared language, collaboration, ethnography, and empathy. They build on the capitals (e.g., background, physical abilities, and education) of the individual and the designer/team. Rather than simply responding to a user's perceived needs, ${ }^{8}$ designers utilise these tools to apply and integrate the insights and awareness of life-expertusers with functional needs to generate holistic solutions for artefacts, services, and interfaces.

\section{Shared language and collaboration}

Shared language promotes communication beyond the superficial. It refers to individuals developing a shared understanding based on language (e.g. spoken, text, body language or visuals), that helps them communicate more effectively, bridging the boundaries of national, social, cultural, technical and professional differences. A shared, common language provides a focus for all stakeholders ${ }^{9}$ and builds on the synergy of the relationships that are developed between individuals. ${ }^{10}$

Collaboration and shared language both require compromise and intention, with a reliance on mutual respect, patience, tolerance and a shared goal. Developing a shared working language helps to define and sometimes redefine terms, language and processes in order to reduce the need for translation amongst collaborators. This process is both challenging and rewarding as teams work to design 'with' the user rather than 'for' the user. ${ }^{7,10}$ Real understanding occurs when the parties are 'on the same page'. This is particularly important when people come from different disciplines or backgrounds. ${ }^{12}$ 


\section{Observing authentic human behaviour:}

Anthropology and ethnography:

"The real act of discovery consists not in finding new lands, but in seeing with new eyes." (Marcel Proust)

Anthropologists venture into the field to observe and record (ethnography) how people interact with products, services and experiences (authentic human behaviour). They develop the ability to "see" things that have gone unnoticed, and what others have failed to comprehend because they stopped looking too soon. ${ }^{13}$

Empathic research strategies incorporate applied ethnography (observation, interview, and conversation with real people) ${ }^{14}$ as exploratory rather than evaluative methods. Applied ethnography reveals more and provides greater insights than the single perspective of 'what people say', since people often say they do one thing, yet actually do another, while feeling still another way about the experience. ${ }^{15,16}$

In Figure 7a, a doctor uses an otoscope. His physical stance demonstrates an area of opportunity in the development of a new high-tech product. The user-experts in Figures $7 \mathrm{~b} \& \mathrm{c}$ have physical disabilities that require them to approach mundane tasks in unexpected ways.

Figure 7a,b,c: Ethnographic recordings of expert-users.

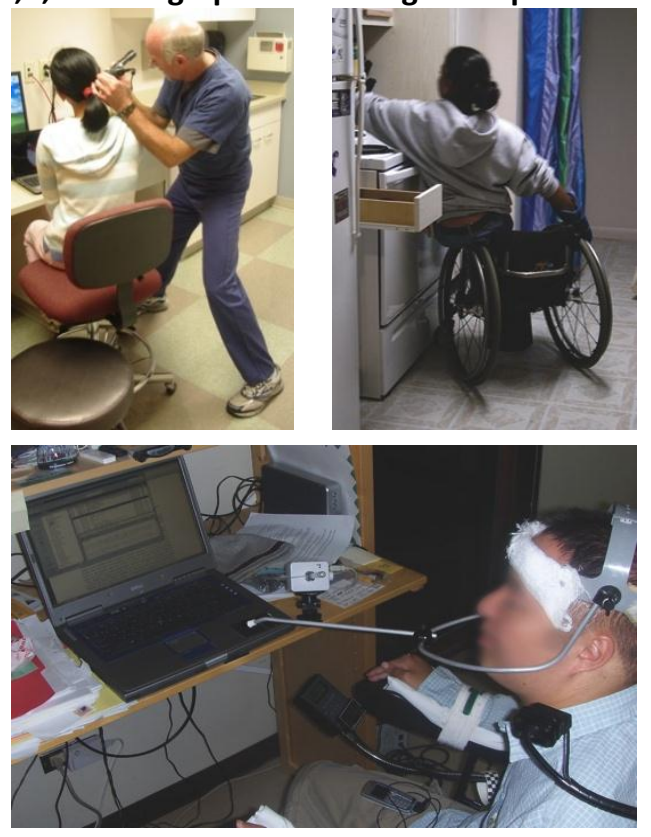

\section{Empathic modelling}

Empathic modelling (experiencing with your own body the physical situations of others) is a strategy that helps to stretch a person's empathic horizon. Within this process, there are multiple layers in the empathic modelling experiences: gaining a surface understanding of another's point of view, developing a deeper understanding through a more thorough empathic modelling process, gaining empathy with another human, and developing an emotional connection with another human being.

The authors developed a course titled 'Disability + Relevant Design' in order to enable young designers to learn to design for others rather than just for themselves. Industrial design students collaborated with other students who had physical disabilities. Empathic modelling (e.g., limited mobility, impaired vision or hearing) was the technique used to take them radically outside their comfort zones. The long-term result has been that students who have participated in this course have demonstrated increased sensitivity to and respect for others, and have continued to practice empathic research during their education.

Figure 8 illustrates an introductory group empathic modelling activity that simulates retinitis pigmentosa (e.g., tunnel vision). These 'disability goggles' are low tech, can be made quickly and represent low risk in immediately immersing a person into the experience of another.

Figure 8: Disability goggles group activity.

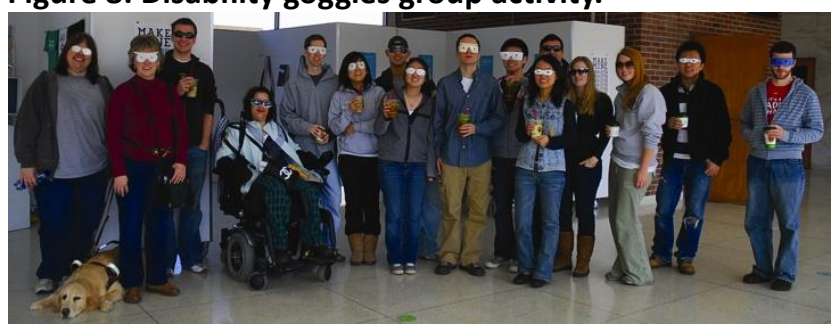

For designers, exploring the needs of users who are significantly different from them is an extremely useful experience (Figure 9). We all approach others with our own assumptions and preconceptions until we learn something different or contradictory. This is why empathic modelling is so important; it pushes people to better understand their own values and belief systems, which result in a move towards less 'projection' of their own perceptions onto others.

Empathic modelling of activities can support a change/shift in a person's thinking. The emotional connection in the modelling experience is the energy that transforms the experience, providing empathic understanding, resonance, deeper appreciation, and helps designers ensure the outcome is relevant to the users. 
Figure 9: Modelling the experience of another - caring for an infant for a week, using assistive devices, limiting range of motion and dexterity.

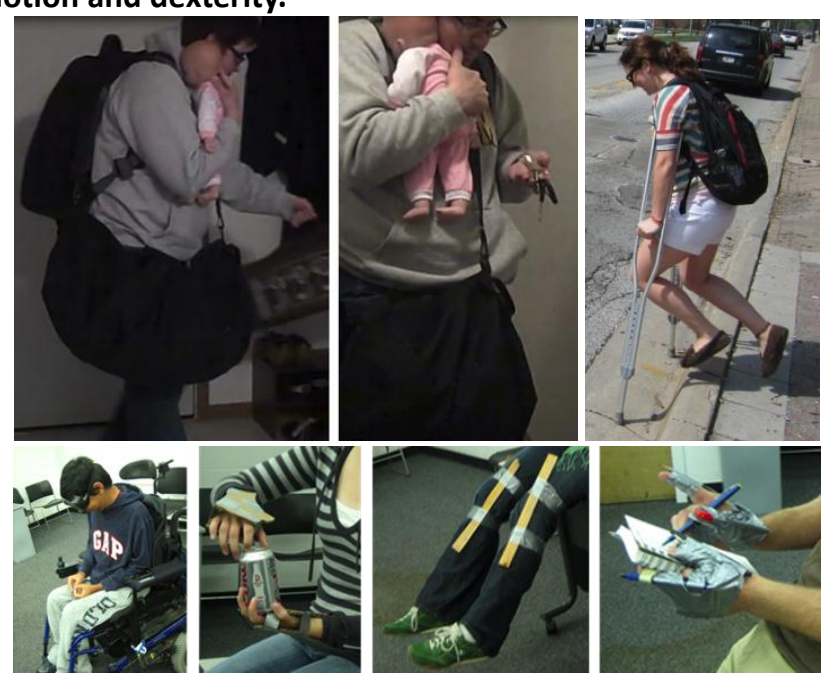

\section{The challenges and the future}

Empathic research strategies are about going beyond traditional research approaches and methods, where the researcher is objective and distant from the subject. Empathic research engages the designer (researcher) and user (subject) as collaborators, who together develop knowledge and understanding in order to generate appropriate solutions for real needs.

The authors' work recognises that the client/user/audience is at the heart of human-centered designing. Due to shifting demographics and emerging populations that do not always conform to a universal ideal, designers need to be receptive and responsive to heterogeneity and changing needs of users more than ever, as do healthcare providers. Significant shifts in personal and social engagement are expected to occur in the near future. A focus on lived experiences of users offers product developers a significant resource to bridge the gulf between existing product solutions and future design outcomes, that have the potential to enhance innovation and greatly enhance the quality of lives for all. Understanding people and addressing their wants, needs, and desires offers a new competitive advantage; that is, by integrating the marginalized voices of end users, product developers of tomorrow are encouraged to question their personal values and beliefs. In the process, they subsequently gain invaluable insights, awareness, and sensitivities.

In the case of healthcare, using empathic strategies is a way of encouraging the development of more effective products and services. This approach can also serve to further develop and deepen the humanistic-centered approach in the education of healthcare practitioners.
Empathy is a way that you can access the voice of end users who have been marginalised. The why builds product integrity; it also inspires people to buy-in to your product. Empathic research strategies are not solutionseeking, but problem-finding.

\section{References}

1. Sinek S. Start with Why: How Great Leaders Inspire Everyone to Take Action. New York: Portfolio Trade; 2009.

2. Americans with Disabilities Act. United States Department of Justice. Available from: http://www.ada.gov. Updated 2010. Accessed December 1, 2012.

3. Weightman D, McDonagh D. People are doing it for themselves. In: Proceedings of the International Conference on Designing Pleasurable Products and Interfaces. Pittsburgh, Pennsylvania: ACM Press; 2003: 34-39.

4. Fulton SJ. Empathic design: Informed and inspired by other people's experience. In: Koskinen I, Battarbee K, Mattelmäki T, eds. Empathic design: User experience in product design. Helsinki, Finland: IT Press; 2003: 52.

5. Denton $\mathrm{H}, \mathrm{McDonagh} \mathrm{D}$. Using focus group methods to improve students' design project research in schools: drawing parallels from action research at undergraduate level. International Journal of Technology and Design Education. 2003; 13(2): 129144.

6. Laurel B. Design research: methods and perspectives. Cambridge, MA: MIT Press, 2003

7. McDonagh D, Thomas J, Khuri L, Heft SS, Peña-Mora F. Empathic Design research strategy: People with disabilities designing for all. In: Silva A, Simoes R, eds. Handbook of Research on Trends in Product Design \& Development: Technological \& Organizational Perspectives. Hershey, Pennsylvania: IGI Global; 2010.

8. Holt M. 'The Limits of Empathy: Utopianism, Absorption and Theatricality in Design'. In: McDonagh D, Thomas J, eds. The Design Journal, Special Issue Empathy and Design; 2011; 2: 150-162.

9. Blackburn B and Williamson R. Pressing forward with professional development. Principal Leadership. 2010; 68-70. Available from: http://barbarablackburnonline.com/app/download/6 480569804/Staff+Development+(Principal+Leadership ).pdf

10. Khuri ML. Working with emotion in educational 
intergroup dialogue. International Journal of Intercultural Relations. 2004; 28: 595-612.

11. McDonagh D, Thomas J, Strickfaden M. Empathic Design Research: Towards a new mode of industrial design education. Design Principles \& Practices: An International Journal. 2011; 5(4): 301-314.

12. Dong $A$. The latent semantic approach to studying design team communication. Design Studies. 2005; 26(5): 445461.

13. Kelly T, Littman J. The ten faces of innovation. New York, NY: Doubleday, 2005.

14. Formosa D. The Six Real People. In: Proceedings of the International Association of Societies of Design Research. Coex, Seoul, Korea (18-22 October). Kyunggi-do: Korean Society of Design Science [CDROM]; 2009.

15. Elwell M, McDonagh D. Empathy for the most vulnerable: Reducing Sudden Infant Death Syndrome and accidental suffocation and strangulation in bed. Design Principles and Practices: An International Journal. 2011; 5(5): 99116.

16. Sanders E. How "applied ethnography" can improve your NPD research process. PDMA Visions, 2002; 8-12.

\section{ACKNOWLEDGEMENTS}

Megan Strickfaden - we could not have done it without you!

\section{PEER REVIEW}

Not commissioned. Externally peer reviewed.

\section{CONFLICTS OF INTEREST}

The authors declare that they have no competing interests. 